\title{
Paralysis Analysis: Investigating Paralysis Visit Anomalies in New Jersey
}

\author{
Teresa Hamby*1, Stella Tsai ${ }^{1}$, Carol Genese ${ }^{1}$, Andrew Walsh ${ }^{2}$, Lauren Bradford ${ }^{2}$ and \\ Edward Lifshitz ${ }^{1}$
}

${ }^{1} \mathrm{NJ}$ Department of Health, Trenton, NJ, USA; ${ }^{2}$ Health Monitoring Systems, Inc, Pittsburgh, PA, USA

\section{Objective}

To describe the investigation of a statewide anomaly detected by a newly established state syndromic surveillance system and usage of that system.

\section{Introduction}

On July 11, 2012, New Jersey Department of Health (DOH) Communicable Disease Service (CDS) surveillance staff received email notification of a statewide anomaly in EpiCenter for Paralysis. Two additional anomalies followed within three hours. Since Paralysis Anomalies are uncommon, staff initiated an investigation to determine if there was an outbreak or other event of concern taking place. Also at question was whether receipt of multiple anomalies in such a short time span was statistically or epidemiologically significant.

\section{Methods}

In New Jersey, 68 of 81 total acute care and satellite Emergency Departments (EDs) are connected to EpiCenter, an online syndromic surveillance system developed by Health Monitoring Systems, Inc (HMS) that incorporates statistical management and analytical techniques to process health-related data in real time. Chief complaint text is classified, using text recognition methods, into various public health-related and other categories. Anomalies occur when any of several statistical methods detect increases in incoming data that are outside of established thresholds.

After receiving three anomaly notifications related to Paralysis in a 4-hour time period, NJDOH surveillance data staff enlisted CDS and local epidemiologist colleagues to review the data and determine if there was an infectious cause.

\section{Results}

The first EpiCenter anomaly notification was received on July 11, 2012 at 1:22 pm as a result of increased ED visits classified as Paralysis based on facility location for the period beginning at noon on July 10, 2012. Using Cusum EMA analysis, 76 reported interactions exceeded the predicted value of 50.49 and the threshold of 70.72 . The second anomaly, also based on facility location, was received at 3:20 $\mathrm{pm}$ and the third anomaly notification, based on home location, was received at 4:32 pm. Cusum EMA and Exponential Moving Average analysis methods detected these anomalies. Table 1 describes the anomalies in more detail.

Compiled data from all anomalies were reviewed by CDS epidemiology and surveillance staff to determine whether there was a public health event taking place. A total of 89 patients were seen in $39(57 \%)$ of the $68 \mathrm{NJ}$ facilities reporting to EpiCenter with no geographic centralization. Age and gender of patients were reviewed with no clear pattern discerned. Figure 1 shows the time distribution of these visits. Upon further investigation, it was determined that a moderate increase in Paralysis visits over a relatively short time span was sufficient to create an anomaly under the default threshold for those visits. Multiple analysis methods created multiple anomalies which gave an impression the event was of greater significance compared to a single anomaly. To follow up, NJDOH requested that local epidemiologists investigate within their jurisdictions by contacting hospitals directly where EpiCenter data proved inconclusive. Their reports confirmed NJDOH's findings that the anomalies did not signal an event of public health concern.

\section{Conclusions}

This investigation of three Paralysis anomalies is an important introduction to the newly implemented system's capabilities in anomaly detection, and also to anomaly investigation procedures developed by NJDOH for local surveillance staff. As a result of this experience, these anomaly investigation procedures are being fine-tuned. The fact that these sequential anomalies resulted in an investigation being undertaken highlights the importance in setting investigation- generating alert thresholds within EpiCenter at a level that will minimize "false" positives without risking the missing of "true" positives.

TABLE 1: Anomaly Details

\begin{tabular}{|c|c|c|c|c|c|}
\hline $\begin{array}{c}\text { Anomaly } \\
\text { Date/Time }\end{array}$ & $\begin{array}{c}24 \text { hour end } \\
\text { time }\end{array}$ & Location & Analysis Method & $\begin{array}{c}\# \\
\text { Interactions }\end{array}$ & $\begin{array}{c}\text { Expected Value/Threshold } \\
\text { of Alert }\end{array}$ \\
\hline $\begin{array}{c}7 / 11 / 2012,1: 22 \\
\text { PM }\end{array}$ & $12: 00 \mathrm{PM}$ & $\begin{array}{c}\text { By } \\
\text { Facility }\end{array}$ & Cusum EMA & 76 & $50.49 / 70.72$ \\
\hline $\begin{array}{c}7 / 11 / 2012,3: 20 \\
\text { PM }\end{array}$ & $2: 00 \mathrm{PM}$ & $\begin{array}{c}\text { By } \\
\text { Facility }\end{array}$ & $\begin{array}{c}\text { Exponential Moving } \\
\text { Average }\end{array}$ & 80 & $50.47 / 79.64$ \\
\hline $\begin{array}{c}7 / 11 / 2012,4: 32 \\
\text { PM }\end{array}$ & $3: 00 \mathrm{PM}$ & By Home & Cusum EMA & 70 & $44.94 / 66.32$ \\
\hline
\end{tabular}

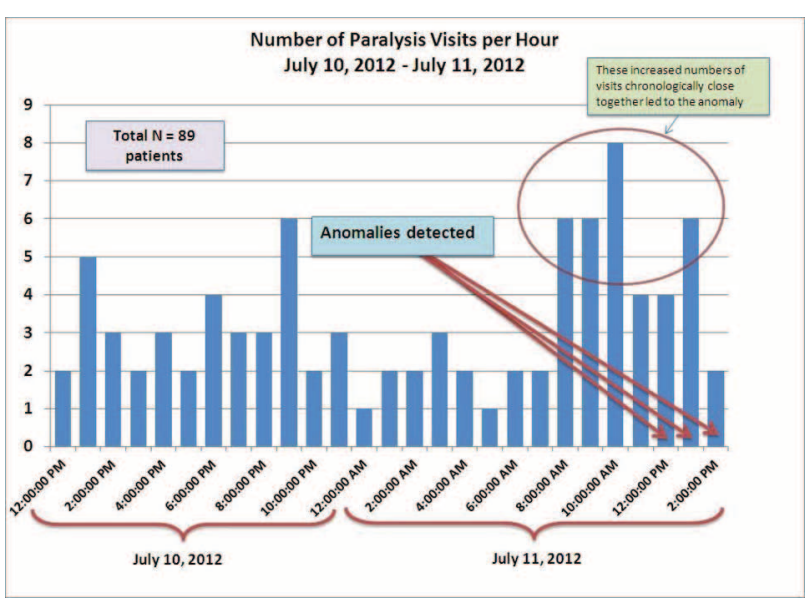

Keywords

Syndromic; Surveillance; Investigation

\section{Acknowledgments}

NJ LINCS Epidemiologists, NJ DOH Epideimologists, NJ DOH Surveillance Staff

*Teresa Hamby

E-mail: Teresa.Hamby@doh.state.nj.us 